2019-02-22

\title{
Dental practice in the UK in 2015/2016. Part 4: changes since 2002?
}

\author{
Burke, FJT
}

http://hdl.handle.net/10026.1/13407

10.1038/s41415-019-0009-0

British Dental Journal

Springer Nature [academic journals on nature.com]

All content in PEARL is protected by copyright law. Author manuscripts are made available in accordance with publisher policies. Please cite only the published version using the details provided on the item record or document. In the absence of an open licence (e.g. Creative Commons), permissions for further reuse of content should be sought from the publisher or author. 


\title{
Dental practice in the UK in 2015/2016: Part 4:
}

\section{Changes since 2002?}

\author{
F.J Trevor Burke, ${ }^{1}$ \\ Nairn H.F. Wilson ${ }^{2}$ \\ Paul A Brunton ${ }^{3}$ \\ Siobhan Creanor ${ }^{4}$
}

1: Primary Dental Care Research Group, University of Birmingham School of Dentistry, College of Medical and Dental Sciences, 5 Mill Pool Way, Pebble Mill, Birmingham B5 7EG, UK

2. Emeritus Professor of Dentistry, King's College London, nairn.wilson@btinternet.com

3. Sir John Walsh Research Institute, Faculty of Dentistry, University of Otago, 310 Great King Street, Dunedin, 9054, New Zealand.

4. Medical Statistics, Plymouth University Peninsula Schools of Medicine and Dentistry, Plymouth Science Park, 1 Davy Road, Plymouth, PL6 8BX

Contact details:Voice: 00441214665476

Email f.j.t.burke@bham.ac.uk burke Wilson creanor brunton4 v6 27 feb18 


\section{ABSTRACT}

\section{OBJECTIVES}

To determine, by means of anonymous, self-report questionnaires, the changes in demographic profile, practicing details and utilization of clinical techniques/materials of general dental practitioners in the UK between 2002 and 2015.

\section{METHODS}

A wide-ranging, validated questionnaire, designed to elicit information on the practicing arrangements and techniques and materials used, was distributed to UK-based general dental practitioners in 2002, 2008 and 2015 with a request that they complete the questionnaire and return it by post in the reply-paid envelope to the corresponding author.

\section{RESULTS}

One thousand questionnaires were distributed by post to 1,000 UK-based general dental practitioners in 2004 and 2008, with 500 questionnaires being distributed at postgraduate meetings in 2015. Response rates of $70 \%, 66 \%$ and $78 \%$ were achieved, respectively.

Of the respondents, $73 \%$ were male in 2002 , while $67 \%$ and $60 \%$ were male in 2008 and 2015 respectively. In 2002, 65\% were practice principals, falling to $51 \%$ in 2015 . Regarding how patients paid for their dental care, $86 \%$ of respondents in 2002 treated patients within the 
National Health Service (NHS) arrangements, compared with $57 \%$ and $50 \%$ in 2008 and 2015 respectively.

The data collected in 2015 indicated that $55 \%$ of respondents had an intraoral camera, while, with regard to recently-introduced concepts and techniques, $80 \%$ used nickel-titanium files, $47 \%$ used zirconia-based bridgework, $25 \%$ used tricalcium silicate, and $17 \%$ used CAD-CAM restoration. Of great interest, perhaps, is the response to digital radiography/imaging, with the results indicating that by $201574 \%$ of respondents used this form of radiography.

\section{CONCLUSION}

Results from the three surveys indicated that NHS service provision has dropped to $50 \%$. Regarding the staffing of dental practices, just over half the respondents were practice principals. The results also indicated that UK dentists continue to be innovative and forward looking in the techniques that they employ. 


\section{INTRODUCTION}

The practice of dentistry in the UK is subject to a variety of factors, some internal, such as changes in Government regulations, and some external, such as varying exchange rates which may influence the cost of materials and equipment. As a result, it could be expected that dental practice will have changed over the past 15 years. Among the factors potentially influencing this are the increasing numbers of teeth being retained ${ }^{1}$, increased patient expectations, especially in relation to the appearance of their anterior and posterior teeth, the increased and increasing input of social media and the increasing number of large commercial organisations as employers of dentists and providers of patient care. Against this background, three detailed questionnaire-based surveys of "what UK dentists do" were carried out in $2003^{2}, 2008^{3}$ and in $2015^{4-10}$. By 2015, the questionnaire had grown to 121 questions, from 79 in 2002.

It is the aim of the present work to compare the results of the three questionnaires and to identify changes in practice demography, and techniques and materials used.

\section{METHODS}

A self-report questionnaire was designed in 2002, based, in part, on the questionnaire used at that time for an annual Clinical Research Associates (CRA) survey of dentists in the USA. The original 
questionnaire was piloted by 10 dentists in the Manchester area, later versions of the questionnaire being piloted among ten postgraduate dentists who were enrolled on the Masters in Advanced General Dental Practice at the University of Birmingham, UK. A small number of changes were suggested and these were incorporated into the final draft of the questionnaire. The original questionnaire contained 18 sections and 79 questions. The 2008 questionnaire contained 89 questions. By 2015, it had grown to 121 questions, reflecting the growth in new techniques with time, but with the third incarnation of the questionnaire still containing most of the questions included in the original version, although with additions in accordance with the authors' views on changes in contemporary UK dentistry since the previous survey was undertaken.

One thousand dentists were initially recruited to the study, being chosen from databases in North West England and Scotland in $2002^{2}$ and $2008^{3}$ : these questionnaires were distributed by post. In 2015, 500 questionnaires were distributed to dentists who were attending postgraduate dental meetings at which at least one of two of the authors were present (FJTB and NHFW) and who expressed a willingness to complete the lengthy questionnaire ${ }^{4}$. The selection criteria continued to aim to provide a wide geographic distribution of dentists from across the UK. 
The data from the questionnaires were collated and entered into a spreadsheet before being exported for statistical analyses, as detailed in the previous papers ${ }^{2-4}$. As the aim of this paper was to summarise the demographics and current practicing arrangements of UK dentists, there were no formal, pre-specified, hypotheses and thus the presented analyses are of a descriptive nature only. The percentages in the previously-published results, based on the number of respondents who answered each question, were rounded to whole figures.

\section{RESULTS AND DISCUSSION}

Response rates of $70 \%, 66 \%$ and $78 \%$ were achieved in 2002, 2008 and 2015 respectively. These response rates were considered to be $\operatorname{good}^{11}$, especially given the length and detailed nature of the questionnaires used. In each of the three surveys, the sample of general dental practitioners (GDPs) was considered, if not representative of all GDPs, to be sufficient to obtain an informative 'snap shot' of contemporary arrangements and approaches in general dental practice.

Demographic data

- The data indicate the increasing proportion of females in the dental profession in the UK, with the proportion of males dropping from $73 \%$ in $2002^{2}$ to $60 \%$ in $2015^{4}$. The reasons for this are considered 
to be many and varied, in accordance with thinking internationally on the global increased number of females of the profession. In the UK, it may be postulated that females have increasingly achieved better "A" level grades than males at school and viewed dentistry as an attractive career. On the other hand, for reasons also not clear, males may have increasingly been less attracted to dentistry. Further considerations may include the impact which aptitude testing (UKCAT) has had on the gender split in admissions to UK dental schools. More specifically, females, more than males, may increasingly feel that dentistry, rather than medicine, is a profession which is better suited to their lifestyle needs and which allows them the opportunity to work flexibly.

- The data also indicate that the mean age of the dental profession is changing, with mean years since graduation rising from 18 years in 2008 to 20 years in 2015. Increases in the number of younger dentists entering the Dentists Register in recent years, many having qualified in dentistry outside the UK, may largely account for this change ${ }^{12}$.

- The data also indicate that fewer respondents are now practice principals (the majority of whom could be considered to own their practice): $65 \%$ were practice principals in 2002 , falling to $51 \%$ in 2015. Reasons for this may be considered to the negative effect of 
increased bureaucracy associated with practice inspections and the like, not being balanced by the opportunity to be one's "own boss". This is possibly associated with the increased trend towards corporate dentistry -'corporatisation', the attraction of which to some is that the company takes care of the majority of the practice administration, let alone the opportunity to realise capital tied up in practice ownership. Alternatively, could it simply be that a lower percentages of practice principals chose to complete a lengthy questionnaire!

- There may be an association with the rise in corporate dentistry and the findings pertaining to the number of dentists in the practice. In 2002 , of the practices with more than one dentist, $28 \%$ had two, $27 \%$ had three and $14 \%$ had four, while the mean number of dentists was 3.6 in 2008 and 4.2 dentists per practice in 2015 . There was also a trend towards location of the practice being in a town/city centre, with $49 \%$ being in a town or city centre location in 2002 , and $57 \%$ in 2015. This may reflect better transport links to city/town centres and fewer staff recruitment issues in towns and cities compared with rural areas, but such considerations need to be balanced against, for example, higher recurrent costs in town and city centres and more difficulties and costs associated with parking in large conurbations. 
- Regarding practice workload, in $2002,83 \%$ of respondents stated that they treated 10 to 20 patients in a typical session, with NHS dentists seeing significantly more patients than other types of practitioner. In 2008, in the typical respondent's practice, 15 patients were seen per session, equating to 16 minutes per patient, again with more patients being seen in NHS practices. Sadly, on reflection, this question was not included in the 121 question 2015 questionnaire. However, given the high number of patient treatment sessions available on average across the respondents' practices per week, specifically, a mean of 23.9 dentist-delivered patient treatment sessions per week in the latest survey, and the understanding that austerity has driven dentists to at least sustain their high patient attendance figures, it may be concluded that dentists in the UK have shown sustained high patient attendances over the period of the three surveys. The impact of sustained, high patient attendances on quality of care and clinical outcomes in general dental practice in the UK is unknown. Anecdotally, it is understood that GDPs who opt out of NHS service provision ('go private') tend to see fewer patients and believe that the care of their patients and clinical outcomes improve.

- Regarding the number of dental hygienists in each practice, in 2002, $44 \%$ of practices had no hygienist and $37 \%$ had a single hygienist, 
while the mean number of hygienists per practice was 1.1 (full time equivalent, FTE) in 2008 and 1.2 hygienists in 2015. Notwithstanding the number of therapists found to be included in dental practice teams in 2015 , many of whom may have provided hygienist services for at least part of their chairside time, it may be considered surprising that numbers of hygienists has not increased dramatically alongside the supposed increased emphasis on prevention in (in particular, NHS ${ }^{13}$ ) UK dentistry.

- Regarding how patients paid for their dental care, in $2002,86 \%$ of respondents treated "a majority" of patients within the National Health Service (NHS) arrangements, compared with $57 \%$ in 2008 and $50 \%$ in 2015 . The reasons for this may be complex, but are considered to include increasing dissatisfaction among GDPs with NHS fees and/or arrangements, and reported reductions in GDP net incomes from NHS service provision. It is possibly not surprising, therefore, that those members of the UK public who wish to only contribute to the cost of their oral healthcare and, possibly more importantly, those who do not have the wherewithal to pay are finding it increasingly difficult to access NHS dental care. A further factor may be patients increasingly electing to pay for treatments that are not available within the NHS arrangements. Alternatively, they may be prepared to pay to have more time spent on their care 
than appears to be possible within the NHS arrangements (vide supra).

- Regarding the health of dentists, the questionnaires asked: "How many days have you been absent from work in the past year because of ill health". Respondents reported 4 days, on average lost through illness in 2002 and 2008, reducing to a mean reported number of days absent of 2.7 days in 2015 . In contrast to these data indicating that the UK dental workforce has become healthier or suffers fewer infections over, in particular the 2008 to 2015 period, it is suggested that GDPs, despite unprecedented level of stress, are either reluctant, or have found it increasingly difficult to take time off work when suffering everyday ailments. Anecdotal opinion indicates that increasing numbers of patients do not take kindly to their appointments being cancelled, even because of clinician illness. Also, it is understood that there is now such competition in the dental market that GDPs may not wish to risk taking time off, other than for serious illness.

- Regarding the use of practice-based computers, responses in 2008 indicated that $73 \%$ of the respondents' practices used a computerised patient management system, with this figure increasing to $94 \%$ in 2015 . It could be considered worrying that, by $2015,6 \%$ of respondents were not using a computerised system, 
given the potential advantages in retaining and collating data. However, it is of interest to note the increasing role that the Internet now plays in the life of dental practices, with three quarters of practices now having a practice web site and and with one third using Social Media to communicate with patients.

- Although this question was not included in the 2002 survey, the data collected that year indicated that $65 \%$ of respondents' practices had a computer system, principally for use in transmitting payment claims. At that time, analysis indicated that younger dentists were more likely to own a state-of-the-art system.

- On the subject of the Internet, $31 \%$ of practices had an Internet connection in 2002 , compared with $67 \%$ in 2008 , rising to $78 \%$ of respondents in 2015 - a figure which was considered remarkably low, albeit now three years ago. There were no questions on the first two questionnaires regarding whether practices had a web site or used the Internet, let alone smart phones to communicate with patients. Given the increasing impact of computers and smart phones in life in the digital age, it may be anticipated that all but a few dental practices, possibly in rural and remote areas, now have Internet capacity. At the time of writing, dentists can breathe a sigh of relief, given that few of their clinical functions have been 
overtaken by computers and robots in the way that this has occurred, and will increasingly occur in other walks of life.

- Regarding the use of an intra-oral camera, the proportion of respondents who use one regularly to support their clinical practice increased from $21 \%$ in 2002 (with $40 \%$ using it routinely) to $66 \%$ in 2008 , while the data in 2015 indicated that $55 \%$ of respondents owned an intra-oral camera, with $52 \%$ using it routinely. These findings, with the apparent drop-off in the number of intraoral camera owners, may not be considered surprising, given the wide range of devices which may now find application in clinical photography, including intra-oral scanners and smart phones. With the expanding role of clinical photography in clinical record keeping, patient communication and education, notwithstanding its use as a means of defending adverse medicolegal situations, it is anticipated that clinical photography will, if not already, be an integral part of everyday practice and record keeping for practitioners.

\section{Techniques used}

Orthodontics

- Regarding the provision of orthodontics by the respondents, $70 \%$ of respondents in 2008 stated that they "never provided this"; increased slightly to $74 \%$ in 2015 . Given these findings, it may be 
postulated that orthodontic treatment provision is largely provided in specialist practices or secondary care. That said, it is understood that a growing number of GDPs may have been persuaded or enticed to provide at least certain forms of aligner therapy since the time of the 2015/2016 survey - one of many different aspects of general dental practice considered to warrant further research.

Local anaesthesia/sedation

- In 2002, intravenous (IV) sedation was used by $21 \%$ of respondents, compared with $20 \%$ in 2008 and $16 \%$ in 2015 . Nitrous oxide/Inhalation sedation was used by $9 \%$ of respondents in 2002 , $13 \%$ in 2002 and by $8 \%$ in 2015 . Despite fear and anxiety continuing to be one of the major barriers to non-attenders seeking regular oral healthcare, and the provision of conscious sedation having great potential as a practice builder, the use of IV techniques has continued to be provided by a relatively small proportion of GDPs. The apparent reduction in the use of sedation is difficult to explain; the reasons may be considered multifactorial.

- Regarding local anaesthesia (LA), detailed questions on which local anaesthetic was used were not asked until 2015. The results of the latest survey indicating that Articaine is now used by $60 \%$ of respondents, with a possible trend towards Articaine infiltration 
techniques as an alternative to inferior alveolar (dental) blocks. This may not be considered surprising, given the potential for damage to surrounding structures advantages which have been described when inferior alveolar blocks are employed ${ }^{14,15}$.

Infection control

- The detailed responses on use of gloves will not be included in the present work, given that disposable gloves were used routinely by $92 \%$ of respondents in 2002 and $99 \%$ in 2008 . It was assumed that this infection-control measure would have been adopted by all clinicians by the time of the 2015 questionnaire, hence no glove use question was included in the latest survey. Other glove related issues, which it is anticipated are now routine practice, include the use of powder- and latex-free gloves.

- Regarding the use of disposable 3 in 1 syringe tips, these were used by $44 \%$ of respondents in $2002,64 \%$ of respondents in 2008 , rising to $93 \%$ in 2015 , indicating increasing awareness of infection control measures and the ways in which single use devices ('disposables') facilitate and strengthen good infection control practices. It is to be hoped that a priority in years to come will be developments to minimise the environmental impact of single use items.

\section{Contemporary techniques and concepts}


- Regarding magnification, $74 \%$ of respondents in 2002 stated that they never used magnification aids, this finding changing when respondents in 2015 were asked: "What percentage of the time do you use magnification?", the response to this question was: $28 \%$ "never", and $43 \%$ "more than $50 \%$ ". Users of magnification will not need to be reminded of its advantages in diagnosis and treatment. Even for colleagues with $20 / 20$ vision, let alone others, the use of magnification provides a new vista that cannot be visualised by the naked eye. In most, if not all, aspects of clinical dentistry, 'the devil is in the detail'. If you are unable to see the detail, you are not able to deal with the 'devil', which often determines the quality of the clinical outcome.

- Regarding the prescription of zirconia-based crowns and bridges, these were not commercially available in 2002, but had been adopted by $27 \%$ in 2008 , with this figure rising to $47 \%$ in 2015 . These data may be considered to indicate that high strength substrate materials for posterior crowns and bridges are valued by GDPs; however, the most recent questionnaire also identified difficulties associated with zirconia. These difficulties, which lend support to the view that no dental biomaterial is perfect, are discussed in the associated paper ${ }^{5}$. 
- As with zirconia, the use of nickel-titanium files had not been developed in 2002, but quickly gained widespread use, by $61 \%$ in 2008 and $80 \%$ of respondents in 2015 . It is understood that the popularity of nickel-titanium files stemmed from practitioners finding these files to provide a faster, easier and more effective means to complete the preparation of root canals: faster, easier and more effective equating to time (is money) saving, less stressful and reduced risk of postoperative complications and failures, all of which are attractive features to the hard-pressed practitioner.

- Tricalcium silicate materials (for example, Biodentine [Septodont]) were not widely available at the time of the first two surveys, but had been adopted by $25 \%$ of respondents by the time of the 2015 survey - another rapid rise in uptake by GDPs. Perhaps this reflects the effectiveness of these materials in managing deep caries $^{16}$, especially in situations in which the practitioner does not wish to risk a pulpal exposure ${ }^{17}$, or it may have offered some practitioners a means to reduce the time taken to restore deep cavities using lightcured layering prior to the introduction of deep-cure resin composites. With current thinking favouring no linings under posterior composites, other than for therapeutic reasons ${ }^{18}$, the future use of tricalcium silicate materials may be considered uncertain. 
- The first survey did not include a question on fibre-reinforced resin composite bridgework. Results from the 2008 survey indicated that such bridgework was used by $15 \%$ of respondents, rising to only $18 \%$ in the $2015 / 2016$ survey. These findings are considered to indicate that fibre-reinforced resin composite bridgework has found application in a significant minority of practices only. As such, fibrereinforced resin composite bridgework may not be considered to have been a 'game changer'. If and when there may be favourable data on the durability and survival of resin-reinforced resin composite bridgework, this fixed option for the replacement of missing teeth may see an upturn in its application. This situation highlights an increasingly common problem in general dental practice - the launch of new materials and approaches with a limited evidence-base, specifically the absence of robust data on longevity and performance in routine clinical service. Should the practitioner resist using innovative materials until such times that are they evidence-based, or does such a stance deny certain patients stateof-the-art care and leave the practitioner 'behind the curve' in terms of their knowledge and understanding of the value of innovations in dental biomaterials science?

- Regarding CAD-CAM restorations, $5 \%$ of respondents used this technology in 2008 , rising to $17 \%$ in the 2015 survey. This may be 
considered to be a modest increase, given the number of CAD-CAM systems made available commercially between 2008 and 2015, let alone the extensive high profile digital dentistry in contemporary dental literature and media. The potential for CAD-CAM technology in dentistry is widely accepted to be substantial. However, it is possible that GDPs in the UK consider CAD-CAM to be something of a technological, or expensive 'sledge-hammer to crack a nut'. Many situations where CAD-CAM may be indicated can be managed either using a direct minimum intervention approach, or using tried and tested indirect techniques, utilising highly accurate, convenient impression systems, albeit that approaches involving impressions require traditional laboratory support.

- Regarding the respondents' use of implants, there was no question relating to these in the 2002 questionnaire. In 2008, 11\% of respondents undertook both implant surgery and implant-related prosthodontics, rising only slightly to $13 \%$ in 2015 . Has implant dentistry remained in the hands of specialist practitioners and a relatively small proportion of GDPs, or is it expanding in general dental practice? Anecdotally, it is understood that in most developed countries the proportion of practitioners providing implant dentistry is much greater than would appear to be the case in the UK. Alternatively, is the market for implant dentistry in the UK relatively 
small, and possibly 'flat', or the fees UK practitioners considered appropriate for implant dentistry beyond those an element of the market is prepared to accept? Further considerations could include awareness among the profession that the risk of peri-implantitis is significant ${ }^{19}$, limiting the survival of implant retained prostheses, with the possibility of associated medicolegal issues. It is the view of the authors, alongside authorities such as Lindhe ${ }^{20}$ and others ${ }^{21}$, that the dental implant should, in the majority of clinical situations, be regarded as the last restorative option to be considered, rather than the first. Preference in care planning should be given to minimum intervention approaches which offer the prospect of an acceptable clinical outcome, including the opportunity to delay resorting to implant dentistry. Furthermore, it is suggested that implants should be viewed as devices to help in the replacement of missing teeth, not alternatives to natural teeth.

- The initial surveys did not include questions concerning digital radiography/digital imaging. By the time of the 2015/2016 survey, the findings indicated that $74 \%$ of respondents used this technology, indicating widespread adoption and rapid growth of the application of digital imaging in general dental practice in the UK. In addition to all the benefits of the shift to digital imaging, the finding of rapid and widespread adoption highlights the willingness of GDPs in the UK 
to be open to the introduction of new technologies and to be prepared to invest in the interest of increased efficiency and effectiveness.

\section{Preventive dentistry}

- Regarding the use of fluoride, in $2008,20 \%$ of respondents stated that they did not use topical fluoride, this figure dropping to $5 \%$ in 2015. However, in $2015,74 \%$ stated that they used practice-based fluoride gel treatments, an increase from $40 \%$ in 2008 . These data may reflect widespread application of the guidance on fluoride applications in the Delivering Better Oral Health toolkit ${ }^{13}$, together with third party requirements and patient expectations for GDPs to be increasingly preventatively orientated in their provision of oral healthcare.

\section{Bleaching}

- In $2002,35 \%$ of respondents indicated that they provided homebased vital bleaching and $18 \%$ indicated that they provided practicebased bleaching. By 2008, despite continuing regulatory uncertainty over the use of bleaching systems for so-called "tooth whitening", these figures had increased to $81 \%$ and $35 \%$ of respondents, while in 2015 , the corresponding figures were $90 \%$ and $28 \%$, the latter figure indicating that practice-based bleaching was found to have decreased between 2008 and 2015. The most recent survey ${ }^{6}$ also 
included questions on adverse effects of bleaching; the responses in respect of bleaching-related sensitivity perhaps suggesting the reason for the fall in practice-based bleaching. As observed in the Part 2 paper in the present series": "With $90 \%$ of respondents having indicated that they provided home-based, vital bleaching ... the findings confirm that bleaching is as an element of everyday practice". As such it should be included in undergraduate curricula, especially given the risk of difficult to manage tooth sensitivity.

\section{Equipment}

- When asked about their preferred chair-side equipment, $65 \%$ used a cart style of delivery in 2002, $62 \%$ of respondents stated "cart" in 2008 , reducing to $55 \%$ of respondents in 2015 , not therefore indicating any noticeable change in selection of dental equipment design.

- Questions were not asked on light curing units (LCUs) until 2015, when $87 \%$ stated that they used an LED type, with $13 \%$ being halogen. Regarding the frequency by which the output of the respondents' LCUs was checked, 53\% $(n=203)$ stated that they did check the output. It could be considered that these data indicate a need for improved education of dentists in relation to the need to 
test their LCUs, given that an incompletely cured resin composite restoration is likely to perform suboptimally ${ }^{22}$.

\section{Use of rubber dam}

- Rubber dam was not used by $61 \%$ of respondents in 2002 for endodontics, let alone any other procedure, although respondents in the North West of England used this significantly more than respondents in Scotland ${ }^{7}$. By 2008, 29\% of respondents stated that they did not use rubber dam, while, by $2015,85 \%$ used this for endodontics and $31 \%$ for operative dentistry; however, $13 \%$ did not use rubber dam at all. While the use of rubber dam for restorative dentistry may be considered desirable (but not essential), its use in endodontics must be considered nothing other than essential, given the potential for contamination of root canals, notwithstanding the adverse medical and medicolegal circumstances should a patient swallow or inhale an endodontic instrument.

\section{Direct placement restorations}

- When questioned as to material most commonly selected for the restoration of occlusal-proximal cavities in permanent molar teeth, in $2002,90 \%$ of respondents indicated amalgam. This figure fell to $75 \%$ in 2008 and reduced again to $55 \%$ in 2015 . For premolar teeth, the equivalent figures were $86 \%$ in $2002,59 \%$ in 2008 and $40 \%$ in 2015. As indicated in the Part 2 paper in the present series ${ }^{5}$, there 
would appear to have been an historic turning point sometime between 2008 and 2015, when amalgam was no longer the material most commonly selected for the restoration of occlusal-proximal cavities in premolar teeth in the UK. Given the corresponding findings for the selection of amalgam for the restoration of occlusalproximal cavities in permanent molar teeth, together with everincreasing patient expectations of tooth-coloured restorations and the Minamata-related phase down of the use of dental amalgam, it may be anticipated, if it has not yet occurred, that amalgam may no longer be the preferred material of choice for the restoration of occlusal-proximal cavities in permanent molar teeth. With the shift to predominantly the use of resin composite systems for direct restorations in premolar and permanent molar teeth, it is hoped that GDPs will concurrently adopt more preventatively orientated, minimum interventive approaches to the provision of direct restorations in posterior teeth.

- When commenting on their attitude towards the use of amalgam, $60 \%$ in 2002 indicated that amalgam should continue to be used. In $2008,75 \%$ of respondents expressed this view; however, in the 2015 survey this figure fell dramatically to $25 \%$. What cannot be gleaned from the data is the extent to which respondents' views on the continuing use of dental amalgam were influenced by the 
Minamata agreement in 2013. Alternatively, the dramatic fall in 'continue to use' respondents between 2008 and 2015 may have been influenced by other factors, including patients declining to accept restorations of amalgam, possibly associated with the growth of non-NHS care, GDPs responding to growing phenomenon of minimum intervention dentistry and the growing body of evidence that state of the art, quicker and easier posterior composites systems may be found to perform as well restorations of amalgam as evidenced in a number of practice-based studies ${ }^{23-25}$. One way or another, it must be concluded that dental amalgam, which has served good purpose for more than 100 years, has had its day in the UK, which may now begin to catch up with most developed countries in the world in moving towards 'mercury free dentistry' - a relatively small, but none the less important contribution to global actions to reduce the effects of mercury on the environment. This catch up will have a further advantage of eliminating an importance difference in what undergraduate dental students are taught in dental schools and what recent graduates are expected to provide in the way of operative (conservative) dentistry, especially as part of NHS funded care.

- Regarding the use of dentine pins, most respondents $(91 \%)$ used these in 2002. This proportion dropped to $67 \%$ in 2008 and then to 
$34 \%$ in 2015 . It is widely considered that recent improvements in the effectiveness of dentine bonding agents ${ }^{26}$ obviate the need for dentine pins, which have well documented risks and adverse effects on remaining tooth tissues ${ }^{27}$.

\section{Restoration of primary teeth}

- Regarding preformed metal crowns for the restoration of carious and otherwise damaged primary molar teeth, $84 \%$ of respondents had not used these in 2002 and $70 \%$ did not use them in 2008, reducing to $56 \%$ of respondents in 2015 , with $29 \%$ of respondents indicating that they "used them occasionally" only. The so-called Hall Technique, named after Norna Hall, a Scottish dentist who introduced the concept, was an innovative way of using preformed metal crowns ${ }^{28}$. It is now an accepted technique with a growing, positive evidence-base to support its application ${ }^{29}$. It is disappointing to note the slow, albeit steady, reduction in 'non-users' of the Hall technique. As with other trends in clinical practice the explanation is likely to be complex; however, the disappointing rate of translation of an effective innovation into routine clinical practice could usefully be investigated as a test case to better understand and possibly eliminate barriers to new, promising operative techniques being applied to the benefit of patients, especially when 
early, widespread application could resultant in health gains and cost efficiencies.

- Regarding the material most commonly used to restore occlusalproximal cavities in primary teeth, glass-ionomer cement (GIC) was used by $55 \%$ of respondents in 2002 , with $28 \%$ using compomers or resin modified GICs (RMGICs). In 2008, GIC was preferred by an unchanged $55 \%$ of respondents with a further $11 \%$ using compomer or RMGIC). Yet again in 2015 , GIC was the most commonly used material, by $55 \%$ of respondents; there was a shift to $32 \%$ of respondents using RMGIC. The use of dental amalgam for the restoration of primary teeth dropped to $9 \%$ in 2015 from $14 \%$ in 2002. The ease of use and effectiveness of GIC and most recent forms of RMGIC in the restoration of primary teeth may be responsible for these changes in the management of paediatric patients, when co-operation may not always be optimal.

\section{Indirect dentistry}

Luting materials

- Regarding luting materials for the cementation of single unit porcelain fused to metal (PFM) restorations, traditional glassionomer cements were used by $68 \%$ of respondents in $2002,48 \%$ in 2008 and $53 \%$ in 2015. Zinc phosphate cement was used to 
cement single unit restorations by $32 \%$ of respondents in $2002,28 \%$ of respondents in 2008 , dropping to $15 \%$ in 2015 . It may be considered disappointing that a significant minority of GDPs in the UK continue to prefer to use traditional zinc phosphate cement when alternative and luting materials with superior properties and proven reliability are available. This may be seen to be a further example of a reluctance amongst certain GDPs to move with the times, apparently ignoring advances in dental biomaterials science. While it is accepted that a change in the use of materials may pose something of a challenge, such challenges should be met head on, when overcoming them will be to the benefit of patients.

- Resin luting materials possess superior physical properties when compared to glass-ionomer and phosphate luting materials and may be used for the adhesive luting (in conjunction with a dentine bonding agent) of indirect restorations in cases where the retention and resistance form of the preparation is less than ideal ${ }^{30-32}$. Such materials were used by $6 \%$ of respondents in $2002,11 \%$ in 2008 and $14 \%$ in 2015 . Self-adhesive resin cements, which are less technique sensitive than other forms of resin luting material ${ }^{33}$, were not available in 2002. In 2008 they were used by $9 \%$ of respondents, rising to $13 \%$ in 2015 . With such slow uptake, it takes manufacturers many years to recoup the research and development costs of new 
materials, possibly delaying further innovation and advances. In the future interests of patients and all stakeholders in the provision of oral healthcare, it is suggested that more rapid uptakes of materials, which represent a tangible advancement in the art and science of dentistry, would be a win-win situation for all involved.

\section{Crown materials}

- Regarding the choice of material for indirect restoration of anterior teeth, all-ceramic was favoured by $20 \%$ of respondents in 2002 and $31 \%$ in 2008 . In 2015 , this percentage was not found to have changed, $31 \%$ of respondents having indicated that they provided all-ceramic crowns. These data may be taken to indicate that the majority of GDPs failed to be impressed with innovations in allceramic to the time of the 2015 survey. Alternatively, the selection of crown type for anterior teeth was, and may continue to be, influenced by factors such as cost, familiarity, and experience of meeting patients' needs and expectations.

\section{Posts}

- Respondents often used more than one type of post. Indirect cast posts, produced in a precious metal alloy, were preferred by $67 \%$ of respondents in 2002, reducing to $55 \%$ using precious metal in 2008 (with 38\% using non-precious metal) and 39\% using precious-metal and $46 \%$ using cast non-precious metal in 2015 . These data indicate 
a swing from precious to non-precious metal, possibly on grounds of cost.

- Fibre posts were scarcely available in 2002 , but the proportion of respondents using them was $26 \%$ in 2008 among NHS practitioners and $50 \%$ among non-NHS practitioners. Sixty three percent of respondents used fibre posts in 2015 . This change may be a result of the more aesthetic properties of fibre posts and/or because they may be luted adhesively. Practitioners may also be aware of the reduced risk of root fracture associated with fibre posts when compared to those formed in metal ${ }^{34}$.

Impression materials

- Regarding impression materials for crown and bridge treatment, in 2002 addition-cured materials were used by $70 \%$ of respondents, condensation cured silicone by $20 \%$ and polyether by $9 \%$. The data indicated that addition-cured silicone was the most commonly used impression material in 2008 (71\% of respondents), with polyether impression materials being used by $17 \%$. In $2015,78 \%$ of respondents indicated that they preferred addition-cured silicone, with $22 \%$ using polyether. The use of condensation-cured silicone having dropped to $10 \%$, perhaps indicating that practitioners are aware of the improved accuracy that can be obtained with alternative materials. 


\section{Postgraduate education}

- In 2002 , a small proportion of respondents (5\%) had not undertaken any postgraduate education in that calendar year - it is interesting to note that compulsory postgraduate education was only introduced in the UK in January 2002. By the time of the 2008 survey, only $2 \%$ of respondents stated that they had attended zero courses (while 63\% had attended 5 or more), while in 2015 , the figure for zero courses was nil, with $79 \%$ of respondents indicating that they had attended 5 or more courses per year, which could be considered to be substantially more than the 15 hours of verifiable CPD required by the UK's General Dental Council for dentists to remain on the Dentists Register. These data may be considered heartening, insofar as they indicate a willingness of the UK dental profession to keep their education up to date.

\section{GENERAL DISCUSSION}

The response rate to the questionnaire was considered good in each distribution and compares favourably with previously-reported response rates to mailed questionnaires ${ }^{10}$. In the previous papers ${ }^{2-4}$, it has been argued that the results may be considered representative of UK dentists at large, so it may be considered that the comparison between the results of the three surveys provides valid information on the changing 
demography of UK dentistry and the changes in the use of techniques and materials.

It is acknowledged that, for practical reasons, not all aspects of clinical practice were investigated in each of the three surveys and, as a consequence, this overview paper does not report, let alone comment on, all changes and trends in general dental practice over the period between 2002 and 2015. The following key findings do, however, give an indication of the dynamic nature of general dental practice in the UK, some of which is encouraging, while other aspects may be considered disappointing, possibly even cause for concern.

It is widely claimed that the rate of introduction of new approaches, materials and devices will continue to increase in the foreseeable future, posing many different challenges to GDPs, especially those working in financial constrained circumstances. With the anticipated increased rate of innovation and change in, for example, dental biomaterials, with enhanced performance in clinical service, it is considered unlikely that many core elements of evolving oral healthcare provision will have a strong evidence base, unless there is new opportunity and support to conduct robust practice-based research, including, for example, 'big data' and related patient outcomes methodologies. 


\section{KEY FINDINGS}

- Satisfactory response rates were obtained for each of the three questionnaires

- There is an increasing number of females in the dental profession in the UK, and the profession, at large, is getting younger

- Fewer dentists are electing to be practice principals

- The number of hygienists employed has not increased substantially

- A smaller proportion of patients is receiving NHS treatment in 2015 than in 2002

- Dental practices are becoming increasingly reliant on computers and increasing numbers are using the internet

- An increasing proportion of UK dentists own an intra-oral camera and increasing numbers are using magnification

- The prescription of zirconia-based crowns and bridges has increased, as too has the use of nickel-titanium files

- The use of fibre-reinforced resin composite bridgework has not increased substantially over the time of the past two surveys

- The prescription of home-based vital bleaching has increased in each survey, but the use of practice-based bleaching decreased between 2008 and 2015. 
- Rubber dam is still not used by all dentists when carrying out root canal treatment

- Dentists who undertook implant surgery and/or prosthodontics barely increased over the two most recent surveys

- The use of amalgam has dropped substantially for restoration of both permanent and primary teeth

- Glass-ionomer cements continue to be most commonly used material for the restoration of primary teeth

- Regarding luting materials for cementation of single unit PFM restorations, traditional glass-ionomer cements have remained popular throughout the three surveys, although the use of resin luting materials has increased

- The use of condensation cured silicone impression materials dropped over the period of the three surveys

- Dentists' attendance for postgraduate education has increased

\section{Acknowledgment}

The authors wish to acknowledge the part played by colleagues in general dental practice in generating the findings presented in this paper. The lengthy survey questionnaires were completed with no incentive or reward. 



\section{REFERENCES}

1.Steele JG, Treasure ET, O'Sullivan I, Morris J, Murray JJ.

Transformations in British Oral Health 1968-2009.

Br.Dent.J.2012:212:523-527.

2.Burke FJT, Wilson NHF, Christensen GJ, Cheung SW, Brunton PA.

Contemporary dental practice in the UK: demographic and practising arrangements. Br Dent J 2005; 198: 39-43.

3.Brunton PA, Burke FJT, Sharif MO, Muirhead EK, Creanor S.

Contemporary dental practice in the UK: demographic details and practising arrangements in 2008. Br.Dent.J. 2012:212:11-16.

4. Burke FJT, Wilson NHF, Brunton PA, Creanor S. Dental practice in the UK in 2015 -Part 1: demographic and practice arrangements. $\mathrm{Br}$ Dent J Paper submitted for editorial consideration.

5. Jum'ah AA, Creanor S, Wilson NHF, Burke FJT, Brunton PA.

Dental practice in the UK in 2015/2016 - Part 3: Aspects of indirect restorations and fixed prosthodontics. Br.Dent.J. Paper submitted for editorial consideration.

6. Brunton PA, Burke, FJT, Wilson NHF, Creanor S. Dental practice in the UK in 2015 - Part 2: Aspects of indirect restoration and prosthodontics. Br Dent J . Paper submitted for editorial consideration 
7. Wilson NHF, Christensen GJ, Cheung SW, Burke FJT, Brunton PA. Contemporary dental practice in the UK: aspects of direct restorations, endodontics and bleaching. Br Dent J 2004; 197: 753-756.

8.Brunton PA, Christensen GJ, Cheung SW, Burke FJT, Wilson NHF. Contemporary dental practice in the UK: indirect restorations and fixed prosthodontics. Br Dent J 2005; 198: 99-130.

9.Brunton PA, Burke FJT Sharif MO, Creanor S, Hosey MT, Mannocci F, Wilson NHF. Contemporary dental practice in the UK in 2008: aspects of direct restorations, endodontics and bleaching. Br Dent J 2011; 212:6367.

10.Brunton PA, Sharif MO, Creanor S, Burke FJT, Wilson NHF. Contemporary dental practice in the UK in 2008: indirect restorations and prosthodontics. Br Dent J 2012: 212: 115-129.

11.Tan RT, Burke FJT. Response rates to questionnaires mailed to dentists: A review of 77 publications. Int.Dent.J.1997:47:349-354.

12.Batchelor P. Registration and retention of dentists on the General Dental Council register between 2006 and 2016. Br.Dent.J.2018:224:105-109.

13. Delivering better oral health: An evidence-based toolkit for prevention. 2017, Public Health England, London. 
14.Pogrel MA, Schmidt BL, Sambarjon V, Jordan RCC. Lingual nerve damage due to inferior alveolar nerve blocks.

J.Am.Dent.Assoc.2003;134:195-199.

15. Haas DA, Lennon D. A 21-year retrospective study of reports of paraesthesia following local anaesthesia administration. J.Can.

Dent.Assoc.1995:61:319-330.

16.Watson TF, Atmeh AR, Sajini S, Cook RJ, Festy F. Present and future of glass ionomer and calcium silicate cements in dentistry: Biophotonics-based interfacial analysis in health and disease. Dent.Mater.2014:30:50-61.

17.Burke FJT. Technique Tips: “A get out of jail material”. Dent.Update 2012:38:300.

18.Blum and Wilson In Press.

19.Warreth A, Boggs S, Ibieyou N, El-Helali R, Hwang S. Peri implant diseases: An overview. Dent.Update 2015:42:166-184.

20.Lindhe $\mathrm{J}$. There is an overuse of implants in the world and underuse of teeth as targets for treatment. Br.Dent.J. 2014:217:396-397.

21. Eliyas S, Briggs $P$, Gallagher JE. The options for a tooth that requires root canal treatment. Dent.Update.2018:45:102-117. 
22.Price RB, Felix CM, Whelan JM. Factors affecting the energy delivered to simulated class I and Class V preparations.

J.Canad.Dent.Assoc.2010:76:a94.

23.Opdam NJM, Bronkhorst EM, Loomans BAC, Huysmanns M-CDNJM.

12 year survival of composite vs amalgam restorations.

J.Dent.Res.2010:89:1063-1067.

24. Laske M, Opdam NJM, Bronkhorst EM, Braspenning JCC, Huysmanns M-CDNJM. Longevity of direct restorations in Dutch dental practices. Descriptive study out of a practice based research network. J.Dent.2016:46:12-17.

25.Palotie U, Eronen AK, Vehkalahti K, Vehkalahti MM. Longedvity of 2and 3-surface restorations in posterior teeth of 25- to 30-year old attending Public Dental Service - A 13 year observation.

J.Dent.2017:62:13-17.

26.Burke FJT, Lawson A, Green DJB, MacKenzie L. What's new in dentine bonding? Universal adhesives. Dent.Update.2017.43:275-283.

27.Bonsor SJ. Are dentine pins obsolete? Dent. Update. 2013:40:253254.

28.Innes NPT, Stirrups DR, Evans DJP, Hall N, Leggate M. A novel technique using preformed metal crowns for managing carious primary 
molars in general practice - a retrospective analysis.

Br.Dent.J.2006:200:451-456.

29. Innes NPT, Ricketts D, Chong L, Keightley AJ, Lamont T, Santamaria.

Preformed crowns for managing decayed primary molar teeth in children.Rhttp://www.cochrane.org/CD005512/ORAL_preformed-crownsmanaging-decayed-primary-molar-teeth-children.

30.Pameijer, $\mathrm{CH}$, Jefferies, SR. Retentive properties and film thickness of 18 luting agents and systems. Gen Dent. 1996;44:524-530.

31.Zidan O, Ferguson GC. The retention of complete crowns prepared with three different tapers and luted with four different cements. J.Prosthet.Dent.2003:89:565-571 .

32. Heintze SD. Crown pull off test (crown retention test) to evaluate the bonding effectiveness of luting agents. Dent.Mater.2010:26:193-206.

33.Burke FJT, Crisp RJ, Richter B. A practice-based evaluation of the handling of a new self-adhesive universal resin luting material. Int Dent J. 2006; 56: 142-146.

34.Bateman G, Ricketts DNJ, Saunders WP. Fibre-based post systems: a review. Br.Dent. J. 2003;195:43-46. 
